\title{
Malaria Disease Distribution in Sudan Using Time Series ARIMA Model
}

\author{
Mohammed I. Musa \\ Economic and Social Research Bureau, Ministry of Science and Communication, P.O. Box 1166, Khartoum, Sudan
}

\begin{tabular}{l}
\hline \hline Article Info \\
\hline Article history: \\
Received Mar 17, 2014 \\
Revised Nov 20, 2014 \\
Accepted Jan 26, 2015 \\
\hline
\end{tabular}

\section{Keyword:}

ARIMA model

ARIMAX

BIC

Malaria cases

Time series

\begin{abstract}
Malaria is widely spread and distributed in the tropical and subtropical regions of the world. Sudan is a sub-Saharan African country that is highly affected by malaria with 7.5 million cases and 35,000 deaths every year. The auto-regressive integrated moving average (ARIMA) model was used to predict the spread of malaria in the Sudan. The ARIMA model used malaria cases from 2006 to 2011 as a training set, and data from 2012 as a testing set, and created the best model fitted to forecast the malaria cases in Sudan for years 2013 and 2014. The ARIMAX model was carried out to examine the relationship between malaria cases and climate factors with diagnostics of previous malaria cases using the least Bayesian Information Criteria (BIC) values. The results indicated that there were four different models, the ARIMA model of the average for the overall states is $(1,0,1)(0,1,1)$. The ARIMAX model showed that there is a significant variation between the states in Sudan.
\end{abstract}

Copyright (c) 2015 Institute of Advanced Engineering and Science. All rights reserved.

\section{Corresponding Author:}

Mohammed I. Musa,

Economic and Social Research Bureau,

Ministry of Science and Technology,

P.O. Box 1166, Khartoum, Sudan.

Email: meage2008@yahoo.com

\section{INTRODUCTION}

The National Malaria Control Programme (2004) declared that malaria is endemic in Sudan; the whole population is at varying degrees of risk. Four main epidemiological malaria areas in Sudan can be identified as follows, high transmission related to irrigation in large irrigation schemes, seasonal malaria related to rainfall in the central parts of Sudan, man-made urban malaria and desert-fringe malaria related to Nile flood [1].

Temperature and rainfall are the most important in the transmission cycle of malaria [2]. Rainfall increases the relative humidity, and, hence, the longevity of the adult mosquito [3], whereas temperature is more critical to malaria transmission through its effect on the duration and survival of the mosquito [4]. Rainfall provides a suitable habitat for the life cycle of the mosquito, but excessive rainfall leads to flush out the mosquito larva. A temperature range of $20^{\circ}-25^{\circ} \mathrm{C}$ increases the longevity of mosquitos; however, extreme temperature will increase mortality [5]. The climate variability plays an important role in starting malaria epidemics in the East African highlands [6].

According to [7]chloroquine is no longer effective in Sudan as the treatment of $P$.falciparum malaria. Therefore, a change in malaria treatment to Aresunate + Sulfadoxine/Pyrimethamine (AS+SP) is recommended for first-line treatment of malaria, while Artemether + Lumefantrineis recommended as the second-line treatment. The third-line is Quinine as well as the drug of choice for severe malaria. Sulfadoxine/Pyrimethamine is recommended for Intermittent Preventive Treatment (IPT) in pregnancy [7].

Control Malaria is poor in most of the African countries and treatment consumes large amounts of health budgets in these countries. Since malaria poses a threat to native populations as well as foreigners. 
Malaria, therefore, not only affects the health status of Africa's population, but also has affects the economy. Malaria disease remains an important public health problem in Sub-Saharan Africa; hence, to develop suitable tools for the control of malaria requires a better understanding of how malaria is distributed within an area [8].

The aim of this study is to forecast malaria cases for 2013 and 2014, and examine the relationship between malaria cases and climatic factors per state in Sudan using Auto-Regressive Integrated Moving Average ARIMA models and the ARIMAX model [9]-[11]. The present study used malaria cases from 2006 to 2011 as a training set, whereas the data from 2012 is used as a testing set, and creates the best model fit to forecast the malaria cases in Sudan for years 2013 and 2014.

\section{RESEARCH METHOD}

\subsection{Study Area}

This study includes all the states of Sudan, namely, Khartoum, Kassala, Al Gazirah, Northern, Sinnar, River Nile, Red Sea, White Nile, Gadaref, Blue Nile, North Darfur, West Darfur, South Darfur, South Gordofan and North Gordofan, as shown in Figure 1. These states vary geographically in terms of climate, ranging from desert in the North, semi-desert and savannah in the centre and south [12]. Temperatures are often high from March until June; from July until October it is mild and rainy, and cold from November to February with low temperature. Malaria transmission is high in the middle of autumn and begins to decrease with continued low temperatures in winter [13].

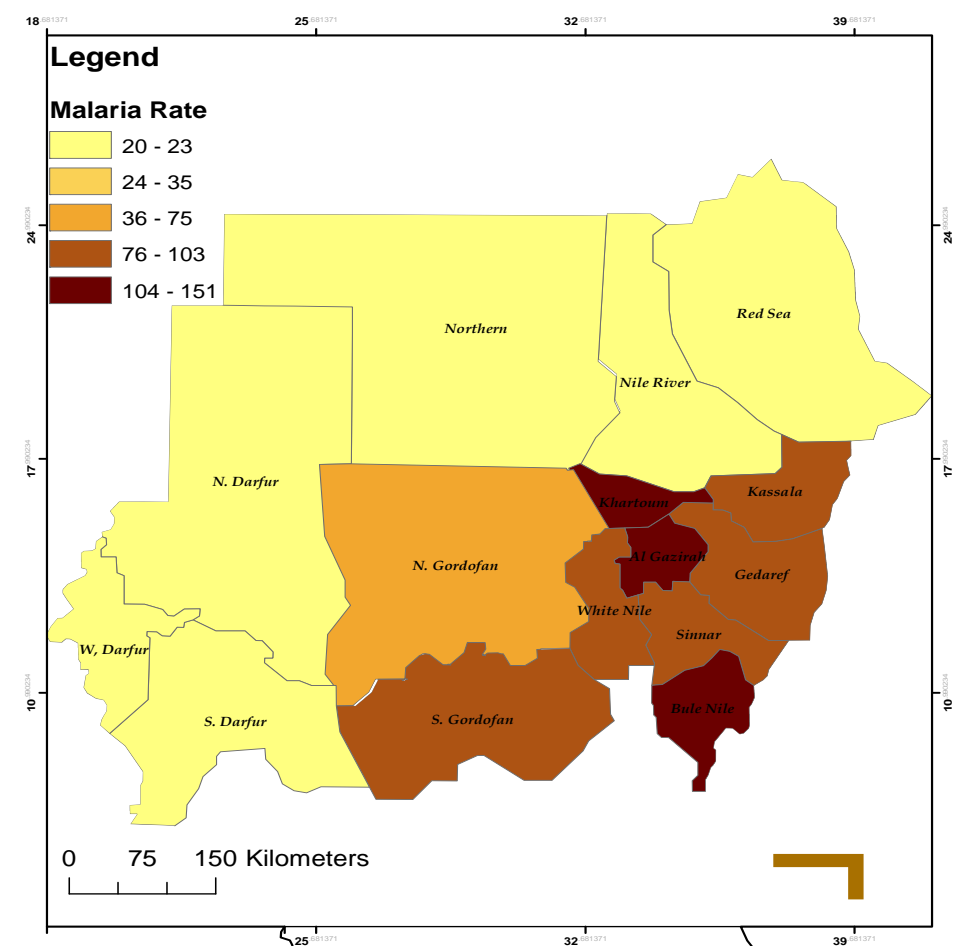

Figure 1. Choropleth map of malaria rate in Sudan for 2006-2011

\subsection{Malaria Data}

The monthly malaria cases were obtained from the National Malaria Control Programme (NMCP), which was established by the Federal Ministry of Health (FMH), Sudan, from years 2006 to 2012. The malaria cases from several levels of health centres, and hospitals are reported to the NMCP every month. These health centres and hospitals provide malaria diagnosis either by demonstration of asexual forms (trophozoite stage) of the parasite in the thick or thin peripheral blood film or by rapid diagnostic test (RDT) in the presence of fever [7].

Malaria distribution varies greatly between the states [12]. Figure 1 shows the malaria rate distribution, which is reported as high in the Central and Eastern states in the study area. The data reflects the aggregated malaria cases at the states level, which varies in quality and may have limited value in 
understanding the actual malaria burden; however, it may be useful for understanding trends in the relative burden of malaria in the public health sector.

\subsection{Meteorological Data}

A climatic record from 2006 to 2012 was obtained from the Sudan Meteorological Authority (SMA). Monthly reported climatic variables include average minimum and maximum temperature, and rainfall. The climate data are collected and recorded at the weather stations in each state. The meteorological unit maintains the records of all the state climatic variables at the central level.

\subsection{ARIMA Model}

Generally, Auto-Regressive Integrated Moving Average (ARIMA) models were popularized by George Box and Gwilym Jenkins in the 1970s; traditionally known as Box-Jenkins analysis[14]. Many previous studies used the ARIMA model in the study of time series of malaria in different parts of the world where there was high malaria transmission.

The present study adopted the non-seasonal Auto-regressive Integrated Moving Average ARIMA $(\mathrm{p}, \mathrm{d}, \mathrm{q})$ and seasonal ARIMA $(\mathrm{P}, \mathrm{D}, \mathrm{Q})^{\mathrm{s}}$ model mentioned by [11], where:

$\mathrm{p}$ is the autoregressive term and $\mathrm{P}$ is the seasonal autoregressive term.

$\mathrm{d}$ is the non-seasonal difference. $\mathrm{D}$ is the seasonal difference.

$\mathrm{q}$ is the moving average parameters. $\mathrm{Q}$ is the seasonal moving average parameters.

$\mathrm{s}$ represents the length of the seasonal period.

A stationary time series is one whose statistical properties, such as mean, variance, do not change over time. In order to obtain consistent and reliable results, the non-stationary data needs to be transformed into stationary data. The present study was making a time series stationary in mean by first removing a trend by differentiation, and, second, removing a seasonal pattern by considering the seasonal AR and MA models combined with a seasonal differencing.

The forecasting ARIMA models were established for each state as well as the overall states. The data from 2006 to 2011 were used as a training set whereas data from 2012 were used as a testing set. The Mean Absolute Percentage Errors (MAPE) was computed. The best model with the least MAPE was used to forecast the malaria cases for the years 2013 and 2014. Before conducting the time series a seasonal ARIMA model of the average overall trend of the malaria data, see Figure 2, shows variability and decreases over time periodically.

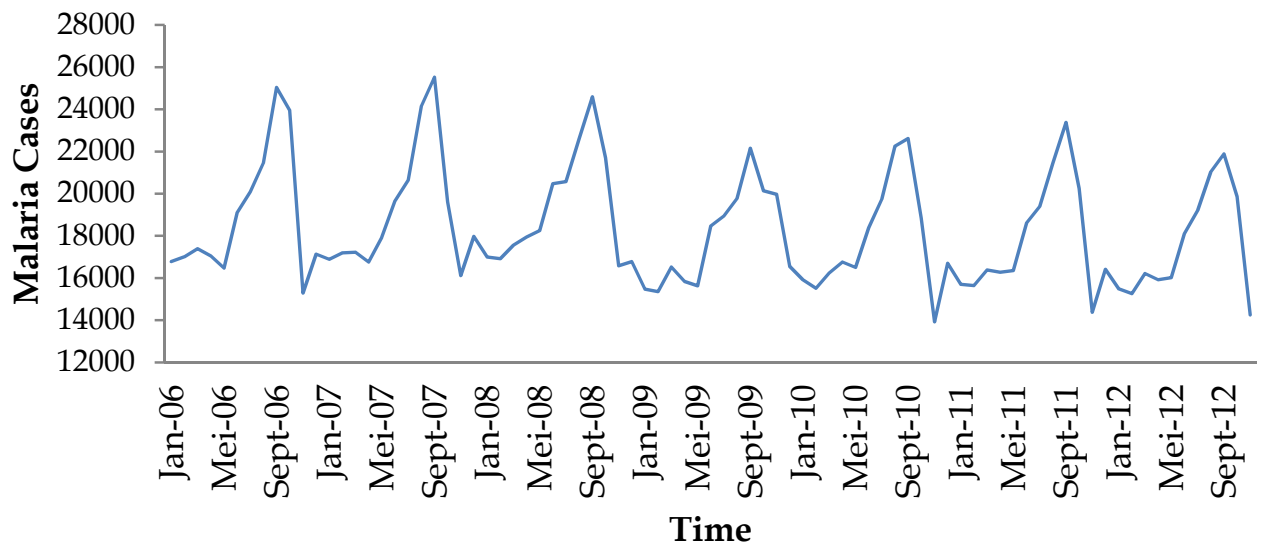

Figure 2. The average malaria cases distribution for overall states from 2006-2012

The Autocorrelation Function (ACF) and Partial Autocorrelation Function (PACF) of the overall states show in Figure 3 the (ACF) is the plot of lags for the first 12 months of the series, to show (ACF) and (PACF). Many lags perforate the blue lines, indicating that the lag(s) is significantly different from zero and the series is not white noise. Furthermore, slowly dies of (ACF) evidence that the data non-stationary and strongly seasonal, it is needed to be differenced. 
Time Series Basic Diagnostics

\begin{tabular}{|c|c|c|c|c|c|c|c|c|}
\hline Lag & AutoCorr & $-.8-.6-.4-.200 .2 .4 .6 .8$ & Ljung-Box Q & p-Value & Lag & Partial & $-.8-.6-.4-.2$ & 0.2 .4 .6 .8 \\
\hline 0 & 1.0000 & & 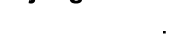 & & 0 & 1.0000 & & \\
\hline 1 & 0.5985 & & 26.8837 & $<.0001^{*}$ & 1 & 0.5985 & & \\
\hline 2 & 0.1808 & & 29.3731 & $<.0001^{*}$ & 2 & -0.2764 & & \\
\hline 3 & -0.0338 & & 29.4613 & $<.0001^{*}$ & 3 & -0.0110 & & \\
\hline 4 & -0.2537 & & 34.5040 & $<.0001^{*}$ & 4 & -0.2918 & & \\
\hline 5 & -0.3709 & & 45.4456 & $<.0001^{*}$ & 5 & -0.0995 & & \\
\hline 6 & -0.3203 & & 53.7280 & $<.0001^{*}$ & 6 & -0.0519 & & \\
\hline 7 & -0.3560 & & 64.1137 & $<.0001^{*}$ & 7 & -0.3129 & & \\
\hline 8 & -0.2632 & & 69.8792 & $<.0001^{*}$ & 8 & 0.0459 & & \\
\hline 9 & -0.0571 & & 70.1552 & $<.0001^{*}$ & 9 & -0.0463 & & \\
\hline 10 & 0.1807 & & 72.9613 & $<.0001^{*}$ & 10 & 0.2002 & & \\
\hline 11 & 0.4923 & & 94.1293 & $<.0001^{*}$ & 11 & 0.3798 & & \\
\hline 12 & 0.6893 & $\vdots \quad: \quad:$ & 136.319 & $<.0001^{*}$ & 12 & 0.2924 & $\vdots:$ & \\
\hline
\end{tabular}

Figure 3. The Plots of ACF and PACF function without differencing

After accounting for the seasonal differences, the data become stationary, which satisfies the normality condition and homogeneity of variance of the residuals, Figure 4.

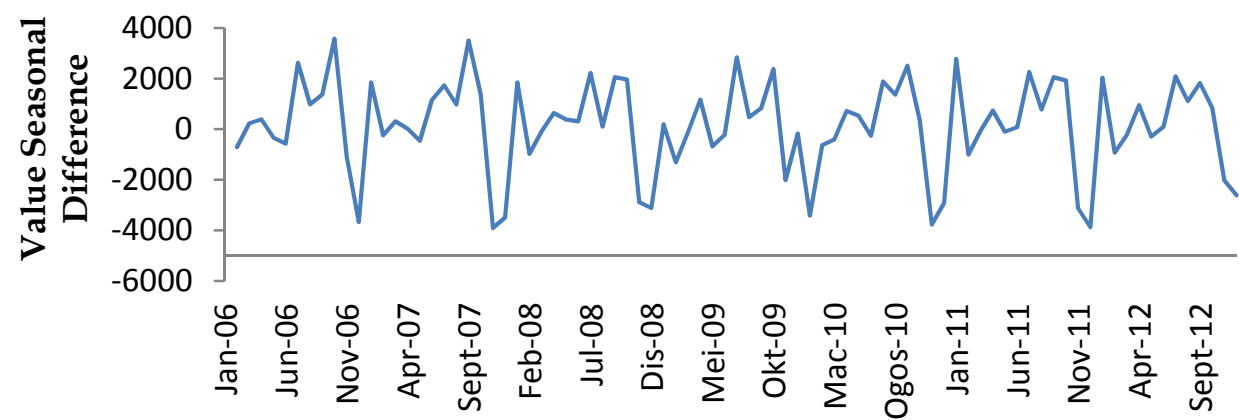

Time

Figure 4. The seasonal difference of malaria cases average overall states 2006-2012

The autocorrelation functions (ACF) and partial autocorrelation functions (PACF), shown in Figure 5, were used to define a suitable model. The forecasting models were developed for each state separately as well as the average for overall states Figure 5.

\begin{tabular}{|c|c|c|c|c|c|c|c|c|}
\hline \multicolumn{9}{|c|}{ Residuals } \\
\hline \multirow{2}{*}{$\begin{array}{r}\text { Lag } \\
0\end{array}$} & \multirow{2}{*}{$\begin{array}{r}\text { AutoCorr } \\
1.0000\end{array}$} & $-.8-.6-.4-.2 \quad 0 \quad .2 .4 .6 .8$ & \multirow{2}{*}{ Ljung-Box Q } & \multirow{2}{*}{ p-Value } & \multirow{2}{*}{$\begin{array}{r}\text { Lag } \\
0\end{array}$} & \multirow{2}{*}{$\begin{array}{l}\text { Partial } \\
1.0000\end{array}$} & \multicolumn{2}{|c|}{-.8-.6-.4-.2 0.2 .4 .6 .8} \\
\hline & & & & & & & & \\
\hline 1 & -0.0091 & & 0.0052 & 0.9426 & 1 & -0.0091 & & \\
\hline 2 & -0.0603 & & 0.2387 & 0.8875 & 2 & -0.0604 & & \\
\hline 3 & 0.1581 & & 1.8693 & 0.6000 & 3 & 0.1575 & & \\
\hline 4 & 0.1151 & & 2.7495 & 0.6006 & 4 & 0.1163 & & "; \\
\hline 5 & -0.0059 & & 2.7518 & 0.7382 & 5 & 0.0156 & & ; \\
\hline 6 & 0.0628 & & 3.0236 & 0.8059 & 6 & 0.0533 & & : \\
\hline 7 & 0.0663 & & 3.3317 & 0.8527 & 7 & 0.0341 & & \\
\hline 8 & -0.0533 & & 3.5350 & 0.8965 & 8 & -0.0625 & & \\
\hline 9 & -0.0227 & & 3.5725 & 0.9372 & 9 & -0.0402 & & $\vdots$ \\
\hline 10 & -0.0522 & $\vdots$ & 3.7753 & 0.9569 & 10 & -0.0933 & & $\vdots$ \\
\hline 11 & 0.0655 & 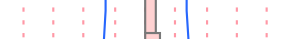 & 4.1010 & 0.9669 & 11 & 0.0667 & & ; \\
\hline 12 & 0.0950 & $\vdots:$ & 4.8008 & 0.9643 & 12 & 0.1150 & & \\
\hline
\end{tabular}

Figure 5. The Plots of ACF and PACF function with seasonal differencing 
The best ARIMA models for malaria data series were investigated and compared with actual cases and predicted cases according to the Mean Absolute Percentage Errors (MAPE) as shown in (Eq. 5.1).

$$
M A P E=100 \% / \mathrm{n} \sum_{\mathrm{t}=1}^{\mathrm{n}}\left(\mathrm{y}_{\mathrm{t}}-\widehat{\mathrm{y}_{\mathrm{t}}}\right) / \mathrm{y}_{\mathrm{t}} \ldots \ldots \ldots \ldots \ldots
$$

Where, $y_{t}$ is the actual value and $\widehat{y_{t}}$ is the forecast value. The best fitting model with the lowest MAPE was used to predict the malaria cases for the year 2012.

The ARIMA models were used to fit the time series malaria data for each state from years 2006 to 2011 and make predictions for year 2012. A comparison of the number of actual and predicted malaria cases for 2012 was carried out. The result is shown in Figure 6 for the all states. The best ARIMA models were selected for different time series data depending on the lower MAPE.

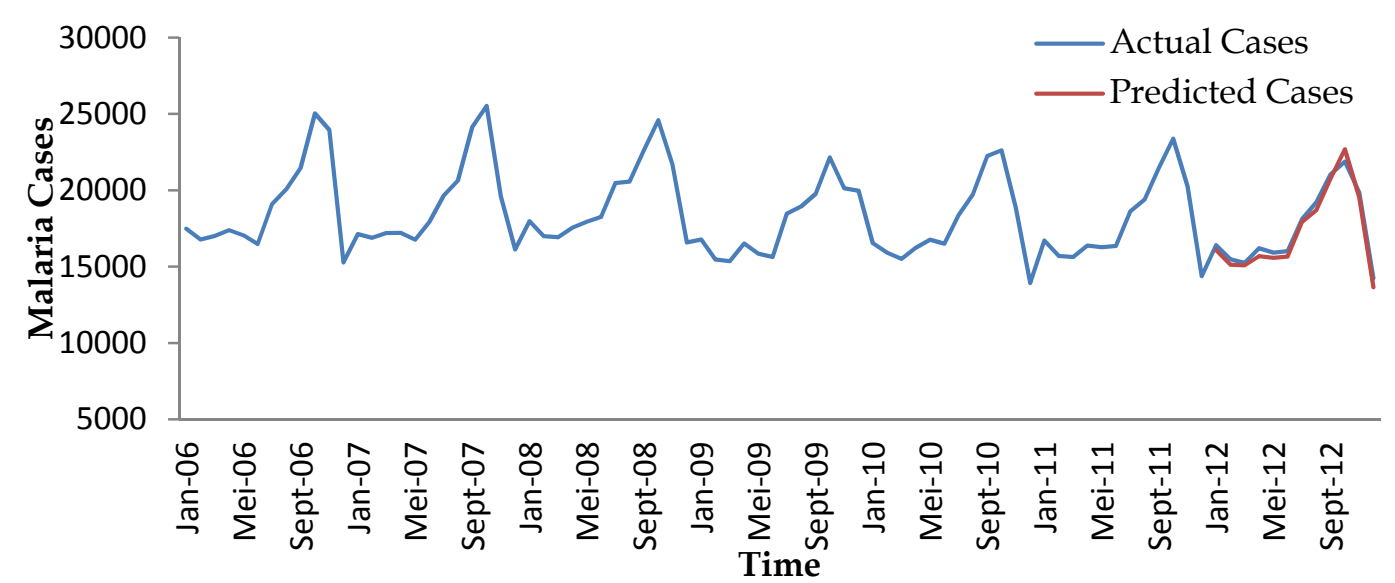

Figure 6. Actual malaria cases from 2006 to 2012 and predicted cases from 2012 for average overall states

\subsection{ARIMAX Model}

The ARIMAX model is one type of ARIMA with predictor variables. The present study adopts the ARIMAX method to predict the malaria cases using climatic factors and the number of malaria cases in the previous month according to Bayesian Information Criteria (BIC) with the formula $(\mathrm{L}-\mathrm{s}(\log \mathrm{N}) / 2)$, where $\mathrm{L}$ is maximum likelihood, $\mathrm{s}$ is number of parameters and $\mathrm{N}$ is number of observations [15] for goodness of fit, where the smallest BIC values with a p-value less than (0.05) measured the best fitting model. The climate factors include the average monthly temperature of maximum and minimum and average monthly rainfall lagged at a period of one month. The ARIMA and ARIMAX model fitting were carried out using JMP, version 9 (SAS Institute Inc., Cary, NC, USA, 2010).

\section{RESULTS AND ANALYSIS}

\subsection{Overall Malaria Incidence}

The trend of overall average monthly malaria cases in Sudan was non-stationary and gradually decreased from 2006 to 2012, as can be seen in Figure 2. The peak period of malaria was observed in July to October when the average cases significantly increased, while the lowest points appeared from December to February for each year. The distributions of malaria fluctuated greatly in the study area, with the high rates concentrated in the middle of the study area, and the lowest rates concentrated in the west and north of the study area, see Figure 1.

\subsection{Malaria Time Series}

The best-fit models of malaria cases for different states and average overall states by using seasonal ARIMA methods from years 2006 - 2011 to predict year 2012 are shown in Table 1. These models were selected based on the least MAPE and a comparison of actual and predicted malaria cases in 2012. The results of the seasonal ARIMA models show that four Groups have different models. The best-fit model for group I include Khartoum, Al Gazirah and Northern states were $(0,1,1)(0,1,1)^{12}$, where the MAPE were 6.81, 7.69 and 12.28, respectively; this group has the forecast equation (5.2). The best-fit model for Group II were 
Kassala, Sinnar, Blue Nile and N Gordofan states were $(1,1,1)(0,1,1)^{12}$, the MAPE were 5.14, 8.23, 5.97 and 6.25, respectively, equation (5.3) for forecasting this Group. The ARIMA $(1,0,0)(0,1,1)^{12}$ model for Group III with MAPE were 10.93 and 8.00, for the states of the Red Sea and Gedaref, respectively, with equation (5.4). While the average overall states, as well as N. Darfur, W. Darfur, S. Darfur, S. Gordofan, White Nile and Nile River, represented in Group IV had MAPE 4.17, 15.02, 13.17, 8.44, 20.20, 8.07 and 7.41, respectively, the best-fit ARIMA model were $(1,0,1)(0,1,1)^{12}$, the forecasting equation model for this group in the equation (5.5).

The forecasting equation model for Group I: $(0,1,1)(0,1,1)^{12}$

$$
\widehat{Y} t=Y(t-12)+(Y(t-1)-Y(t-13))-\Theta e(t-1)-\Theta e(t-12)+\Theta \Theta e(t-13) \ldots
$$

The forecasting equation model for Group II: $(1,1,1)(0,1,1)^{12}$

$$
\hat{Y} t=Y(t-12)+\phi(Y(t-1)-Y(t-13))-\Theta e(t-1)-\Theta e(t-12)+\Theta \Theta e(t-13) . .
$$

The forecasting equation model for Group III: $(1,0,0)(0,1,0)^{12}$

$$
\hat{Y} t=\mu+Y(t-12)+\phi(Y(t-1)-Y(t-13) \ldots(5.4)
$$

The forecasting equation model for Group IV: $(1,0,1)(0,1,1)^{12}$

$$
\begin{gathered}
\hat{Y} t=\mu+Y(t-12)+\phi(Y(t-1)-Y(t-13))-\Theta e(t-1)-\Theta e(t-12) \\
+\theta \Theta e(t-13) \ldots(5.5)
\end{gathered}
$$

\begin{tabular}{|c|c|c|c|c|c|}
\hline \multirow[t]{2}{*}{ Groups } & \multirow[t]{2}{*}{ States } & \multirow[t]{2}{*}{ Model } & \multicolumn{2}{|c|}{ Malaria Cases } & \multirow[t]{2}{*}{ MAPE } \\
\hline & & & Actual & Predicted & \\
\hline \multirow[t]{3}{*}{$\mathrm{I}$} & Khartoum & $(0,1,1)(0,1,1)^{12}$ & 618283 & 619009 & 6.81 \\
\hline & Al Gazirah & $(0,1,1)(0,1,1)^{12}$ & 714061 & 729308 & 7.69 \\
\hline & Northern & $(0,1,1)(0,1,1)^{12}$ & 30989 & 30798 & 12.28 \\
\hline \multirow[t]{4}{*}{ II } & Kassala & $(1,1,1)(0,1,1)^{12}$ & 209667 & 203324 & 5.14 \\
\hline & Sinnar & $(1,1,1)(0,1,1)^{12}$ & 237044 & 235991 & 8.23 \\
\hline & Blue Nile & $(1,1,1)(0,1,1)^{12}$ & 212313 & 208107 & 5.97 \\
\hline & N. Gordofan & $(1,1,1)(0,1,1)^{12}$ & 278957 & 277354 & 6.25 \\
\hline \multirow[t]{2}{*}{ III } & Red Sea & $(1,0,0)(0,1,1)^{12}$ & 22762 & 22097 & 10.93 \\
\hline & Gedaref & $(1,0,0)(0,1,1)^{12}$ & 146868 & 149035 & 8.00 \\
\hline \multirow[t]{7}{*}{ IV } & N. Darfur & $(1,0,1)(0,1,1)^{12}$ & 74546 & 71016 & 15.02 \\
\hline & W. Darfur & $(1,0,1)(0,1,1)^{12}$ & 20187 & 19723 & 13.17 \\
\hline & S. Darfur & $(1,0,1)(0,1,1)^{12}$ & 67138 & 68262 & 8.44 \\
\hline & S. Gordofan & $(1,0,1)(0,1,1)^{12}$ & 135480 & 129584 & 20.20 \\
\hline & White Nile & $(1,0,1)(0,1,1)^{12}$ & 110389 & 113617 & 8.07 \\
\hline & Nile River & $(1,0,1)(0,1,1)^{12}$ & 119249 & 117523 & 7.41 \\
\hline & Overall States & $(1,0,1)(0,1,1)^{12}$ & 209635 & 206502 & 4.17 \\
\hline
\end{tabular}

Where $\phi$ denotes the $\operatorname{AR}(1)$ coefficient, $\Theta$ is MA(1) coefficient and $\Theta$ is $\operatorname{SMA}(1)$ coefficient.

Table 1. Actual and predicted malaria cases of Sudan states

The best model was fitted to forecast the malaria cases in Sudan for years 2013 and 2014, as shown in Tables 2 and 3. Sorting the states in descending order from the highest rates of cases to the lowest is as follows, Al Gezirah, Khartoum, North Gordofan, White Nile, Sinnar, Blue Nile, Kassala, Gadaref, South Gordofan, Nile River, North Darfur, South Darfur, Northern, Red Sea and West Darfur. Al Gazirah state reported the highest forecast number of malaria cases with 708,815 and 705,749, followed by Khartoum state with 593,126 and 568,967 cases in years 2013 and 2014, respectively. The lowest cases were reported by the Northern, Red Sea, and West Darfur states, with malaria cases 29,858, 20,959 and 19,377 in 2013, and $28,650,18,989$ and 18,803 in year 2014, respectively. In general, there was a decrease in the number of malaria cases in year 2014, which was estimated to be about 15\% compared to the year 2006 .

\subsection{Malaria and Predictor Variables}

The ARIMAX models were fitted to the malaria data from 2006 to 2012. The models used the previous malaria cases with climate factors, which included the average monthly temperature of maximum, minimum and rainfall, at lagged one month. Table 4 shows the best fitting model for each state as well as the average of overall states. The best model for the average overall states is model III due to the least value of BIC, which equal to 913.64 , with the p-value of the previous malaria cases equals .017 and p-value of rainfall 
less than .0001 . The states of Khartoum and Kassala are only significant with the previous malaria cases variable; the best model for Khartoum state is model I, which BIC equals 1,127.3, while model II is best for Kassala state. The Northern and Red Sea states have no significance with previous malaria cases and rainfall in the different models; however, the temperature maximum and minimum are significant in the Northern and Red Sea states. Model II was the best model for both the Northern and Red Sea states with BIC equal to 788.92 and 753.73, respectively. Model VI was the best fitted model for Gedaref state with BIC equal to 927.76 with a p-value .003, <.0001 and .005 for previous malaria cases, maximum and minimum temperature, respectively. In model II the p-values of rainfall were significant for all states except Khartoum, Kassala, Northern, River Nile and Red Sea states.

Table 2. Forecasting monthly malaria cases of Sudan states from January to December 2013

\begin{tabular}{|c|c|c|c|c|c|c|c|c|c|c|c|c|c|}
\hline \multirow{2}{*}{ State } & \multicolumn{12}{|c|}{ Forecasted Malaria Cases } & \multirow{2}{*}{ Total } \\
\hline & Jan. & Feb. & March & April & May & June & July & Aug. & Sep. & Oct. & Nov. & Dec. & \\
\hline Kassala & 16823 & 14565 & 17031 & 14503 & 15002 & 14623 & 15612 & 15979 & 17411 & 19441 & 20355 & 17630 & 198975 \\
\hline Gedaref & 11306 & 10025 & 8908 & 10257 & 8941 & 9693 & 11733 & 14325 & 16771 & 18156 & 13674 & 8002 & 141791 \\
\hline Al Gazirah & 59821 & 57824 & 52151 & 55872 & 57105 & 55834 & 57971 & 59895 & 65071 & 75129 & 66329 & 45813 & 708815 \\
\hline Sinnar & 15967 & 12772 & 14621 & 16378 & 18691 & 19462 & 22311 & 27426 & 29465 & 24150 & 18236 & 13012 & 232491 \\
\hline Blue Nile & 12387 & 15215 & 11613 & 13816 & 13649 & 16200 & 21026 & 24343 & 21475 & 24085 & 19885 & 14824 & 208518 \\
\hline White. Nile & 16007 & 20684 & 23492 & 20176 & 12788 & 18337 & 29723 & 27423 & 32854 & 27868 & 11972 & 10058 & 251382 \\
\hline $\begin{array}{l}\text { N. } \\
\text { Gordofan }\end{array}$ & 15400 & 16946 & 16931 & 18730 & 22192 & 20267 & 24115 & 26613 & 29242 & 27061 & 32750 & 21848 & 272095 \\
\hline S. Gordofan & 8661 & 7937 & 7330 & 7123 & 10661 & 13378 & 14381 & 16091 & 13093 & 14435 & 11546 & 5625 & 130261 \\
\hline S. Darfur & 6147 & 2715 & 4034 & 4192 & 3750 & 5565 & 7600 & 7729 & 8228 & 7418 & 5710 & 4056 & 67144 \\
\hline W. Darfur & 1396 & 1055 & 959 & 667 & 538 & 937 & 1565 & 2050 & 3286 & 3245 & 2443 & 1236 & 19377 \\
\hline N. Darfur & 5323 & 3564 & 4271 & 5777 & 6103 & 6909 & 7752 & 8450 & 8326 & 9488 & 5596 & 5445 & 77004 \\
\hline Khartoum & 56088 & 46743 & 48311 & 53768 & 50798 & 38625 & 36681 & 33915 & 49496 & 67950 & 67470 & 43281 & 593126 \\
\hline Nile River & 9670 & 10137 & 8908 & 8302 & 9432 & 9563 & 10508 & 10511 & 10000 & 9794 & 8150 & 6986 & 111961 \\
\hline Northern & 1719 & 2349 & 3463 & 1999 & 1307 & 2353 & 3415 & 2383 & 2608 & 3178 & 3262 & 1822 & 29858 \\
\hline $\begin{array}{l}\text { Overall } \\
\text { States }\end{array}$ & 238774 & 225320 & 224618 & 234046 & 231560 & 233290 & 265722 & 278371 & 308233 & 333088 & 289632 & 201103 & 3063757 \\
\hline
\end{tabular}

Table 3. Forecasting monthly malaria cases of Sudan states from January to December 2014

\begin{tabular}{|c|c|c|c|c|c|c|c|c|c|c|c|c|c|}
\hline \multirow{2}{*}{ State } & \multicolumn{12}{|c|}{ Forecasted Malaria Cases } & \multirow{2}{*}{ Total } \\
\hline & Jan. & Feb. & March & April & May & June & July & Aug. & Sep. & Oct. & Nov. & Dec. & \\
\hline Kassala & 15982 & 13685 & 16132 & 13590 & 14076 & 13685 & 14662 & 15017 & 16436 & 18454 & 19356 & 16619 & 187694 \\
\hline Gedaref & 10890 & 9610 & 8492 & 9841 & 8525 & 9277 & 11318 & 13909 & 16355 & 17740 & 13258 & 7586 & 136801 \\
\hline Al Gazirah & 59518 & 57530 & 51865 & 55595 & 56837 & 55574 & 57720 & 59653 & 64837 & 74903 & 66112 & 45605 & 705749 \\
\hline Sinnar & 15590 & 12407 & 14259 & 16017 & 18332 & 19103 & 21952 & 27067 & 29108 & 23792 & 17879 & 12656 & 228162 \\
\hline Blue Nile & 12111 & 14952 & 11346 & 13551 & 13384 & 15935 & 20761 & 24078 & 21211 & 23821 & 19621 & 14561 & 205332 \\
\hline White. Nile & 15648 & 20309 & 23109 & 19790 & 12401 & 17949 & 29335 & 27034 & 32466 & 27480 & 11583 & 9670 & 246774 \\
\hline N. Gordofan & 14881 & 16426 & 16411 & 18210 & 21672 & 19747 & 23595 & 26093 & 28722 & 26541 & 32230 & 21329 & 265857 \\
\hline S. Gordofan & 7254 & 7024 & 6684 & 6621 & 10237 & 12996 & 14021 & 15744 & 12752 & 14098 & 11210 & 5291 & 123932 \\
\hline S. Darfur & 6127 & 2658 & 3989 & 4143 & 3702 & 5516 & 7552 & 7680 & 8180 & 7370 & 5662 & 4008 & 66587 \\
\hline W. Darfur & 1357 & 1002 & 913 & 617 & 490 & 888 & 1517 & 2002 & 3237 & 3197 & 2395 & 1188 & 18803 \\
\hline N. Darfur & 5460 & 3677 & 4369 & 5863 & 6182 & 6983 & 7823 & 8518 & 8393 & 9554 & 5662 & 5510 & 77994 \\
\hline Khartoum & 54206 & 44838 & 46382 & 51815 & 48821 & 36624 & 34655 & 31866 & 47423 & 65852 & 65349 & 41136 & 568967 \\
\hline Nile River & 9731 & 10175 & 8931 & 8315 & 9439 & 9565 & 10506 & 10508 & 9995 & 9788 & 8143 & 6979 & 112075 \\
\hline Northern & 1625 & 2253 & 3366 & 1901 & 1208 & 2253 & 3314 & 2280 & 2505 & 3074 & 3156 & 1715 & 28650 \\
\hline Red Sea & 1881 & 2660 & 2426 & 2342 & 436 & 1389 & 1160 & 1074 & 735 & 1520 & 2078 & 1288 & 18989 \\
\hline $\begin{array}{l}\text { Overall } \\
\text { States }\end{array}$ & 232261 & 219206 & 218674 & 228211 & 225742 & 227484 & 259891 & 272523 & 302355 & 327184 & 283694 & 195141 & 2992366 \\
\hline
\end{tabular}


Table 4. ARIMAX models, malaria cases and climate factors with previous malaria cases in Sudan

\begin{tabular}{|c|c|c|c|c|c|c|c|c|c|c|c|c|c|c|c|c|c|}
\hline \multirow{2}{*}{$\begin{array}{l}\text { Mo } \\
\text { del }\end{array}$} & \multirow{2}{*}{$\begin{array}{c}\text { Predic- } \\
\text { tor }\end{array}$} & \multicolumn{16}{|c|}{ States* } \\
\hline & & 1 & 2 & 3 & 4 & 5 & 6 & 7 & 8 & 9 & 10 & 11 & 12 & 13 & 14 & 15 & 16 \\
\hline \multirow[t]{3}{*}{ I } & Prev. & .017 & .0001 & .03 & & $<.0001$ & .006 & & $<.0001$ & $<.0001$ & .001 & $<.0001$ & $<.0001$ & $<.0001$ & $<.0001$ & $<.0001$ & $<.0001$ \\
\hline & Max. & & & & .04 & & & $<.0001$ & $<.0001$ & $<.0001$ & $<.0001$ & & & .003 & & & \\
\hline & BIC & 1127.3 & 911.11 & 1067.0 & 789.37 & 996.67 & 851.89 & 754.63 & 1034.6 & 929.68 & 942.99 & 872.50 & 786.33 & 865.85 & 972.15 & 997.39 & 925.42 \\
\hline \multirow[t]{3}{*}{ II } & Prev. & .016 & $<.0001$ & .04 & & .0002 & .006 & & .0004 & $<.0001$ & $<.0001$ & & $<.0001$ & $<.0001$ & $<.0001$ & $<.0001$ & $<.0001$ \\
\hline & Min. & & & .006 & .03 & $<.0001$ & & $<.0001$ & & & & $<.0001$ & & & & $<.0001$ & .009 \\
\hline & BIC & 1127.4 & 911.09 & 1060.1 & 788.96 & 984.12 & 848.74 & 753.73 & 1050.4 & 943.42 & 986.56 & 847.87 & 787.04 & 873.45 & 974.75 & 984.36 & 919.13 \\
\hline \multirow[t]{3}{*}{ III } & Prev. & .015 & $<.0001$ & .04 & & .002 & .003 & & & $<.0001$ & .04 & .0003 & $<.0001$ & & $<.0001$ & $<.0001$ & .017 \\
\hline & Rain. & & & & & .0001 & & & $<.0001$ & .04 & $<.0001$ & $<.0001$ & .04 & $<.0001$ & .007 & .03 & $<.0001$ \\
\hline & BIC & 1127.5 & 911.30 & 1066.4 & 793.80 & 972.86 & 851.12 & 778.30 & 1030.4 & 965.30 & 930.92 & 856.32 & 784.96 & 859.43 & 967.03 & 1000.2 & 913.64 \\
\hline \multirow[t]{4}{*}{ IV } & Prev. & .02 & .0002 & & & .04 & .006 & & .04 & .0001 & & & $<.0001$ & & $<.0001$ & $<.0001$ & .001 \\
\hline & Max. & & & & .04 & & & $<.0001$ & .03 & .001 & .002 & $<.0001$ & & & & .001 & $<.0001$ \\
\hline & Rain. & & & & & $<.0001$ & & & .0009 & & $<.0001$ & $<.0001$ & & $<.0001$ & .01 & .002 & .0007 \\
\hline & BIC & 1131.4 & 915.18 & 1069.3 & 793.30 & 974.31 & 854.94 & 757.94 & 1029.2 & 932.61 & 925.30 & 847.77 & 788.41 & 863.41 & 969.69 & 990.86 & 920.22 \\
\hline \multirow[t]{4}{*}{ V } & Prev. & .02 & .0001 & & & & .005 & & & $<.0001$ & .04 & & $<.0001$ & & $<.0001$ & $<.0001$ & .01 \\
\hline & Min. & & & .016 & .03 & $<.0001$ & & $<.0001$ & & & & $<.0001$ & & & & $<.0001$ & \\
\hline & Rain. & & & & & $<.0001$ & & & $<.0001$ & .007 & $<.0001$ & $<.0001$ & .04 & $<.0001$ & .002 & & .002 \\
\hline & BIC & 1131.5 & 915.17 & 1064.5 & 792.90 & 958.98 & 852.44 & 755.10 & 1033.5 & 941.68 & 934.49 & 827.44 & 786.77 & 860.28 & 968.64 & 984.94 & 914.76 \\
\hline \multirow[t]{5}{*}{ VI } & Prev. & .029 & .007 & & & & .007 & & .008 & .003 & & & $<.0001$ & & $<.0001$ & .0007 & .001 \\
\hline & Max. & & & $<.0001$ & & .03 & & & .002 & $<.0001$ & $<.0001$ & .001 & & .04 & & & .001 \\
\hline & Min. & & & $<.0001$ & & $<.0001$ & .03 & & .04 & .005 & $<.0001$ & $<.0001$ & & .01 & & .01 .01 & \\
\hline & Rain. & & & & & .001 & & & & & .04 & .008 & & $<.0001$ & .007 & & .003 \\
\hline & BIC & 1135.4 & 916.80 & 1050.4 & 796.87 & 958.04 & 853.53 & 759.17 & 1029.8 & 927.76 & 909.61 & 821.46 & 787.03 & 860.39 & 972.44 & 792.44 & 924.30 \\
\hline
\end{tabular}

\section{DISCUSSION}

\subsection{Malaria Time Series Model}

The present study adopted the seasonal ARIMA model and fitted the malaria cases for each state as well as the overall states. The different ARIMA models were found for different states, this indicates that each group has an individual malaria trend. These results are consistent with those of several previous studies, such as [11], who found the existence of different ARIMA models of time-series analysis for the endemic areas of Bhutan. The present study found that the West states, such as N. Darfur, S. Darfur, W. Darfur and S. Gordofan, located in group IV, have the same model trend, and, hence, there is a similarity of malaria disease transmission for these states. In contrast, the other ARIMA model is not consistent with this assumption. Some states, despite their geographical remoteness, are located in one group, while the adjacent states are located in different groups. Khartoum and Al Gazirah states are adjacent and located in group I, which also includes the presence of the Northern state in the same group, despite being geographically located far from these states. Sinnar and Blue Nile states located in group II have the same model, which border each other while Kassala and N. Gordofan had the same model but different geographical locations. Interestingly, some high malaria rate states are close to the very low malaria rate states (see Figure 1). Thus, different malaria ARIMA models were detected along with states that have the same malaria rate and similar climate variables. This result is supported by [11] who concluded that the endemic districts in Bhutan did not follow the hypothesis, which assume that the areas near to each other are expected to have similar disease transmission patterns according to their spatial and climatic similarity in terms of spatial location. The difference in the malaria trend between states, results from the variability of malaria treatment diagnosis control programmes between states and between urban and rural area within state. As well as a number of factors played role in urban malaria epidemics such as construction of new urban colonies without suitable facilities for drainage, influx of refugees, insufficient supply of drugs, alsothe migration from rural to urban

\subsection{Climate Variability and Malaria Model}

The time series ARIMAX model was fitted to the malaria cases with previous malaria cases and predictor variables included (average monthly temperature of maximum, minimum and rainfall lagged at a period of one month). The lagged one month to the climate variability is logical for the period taken by the mosquito and vector life cycle [13]. The previous month's malaria cases indicate the level of human reservoir within the area, while climate factors, such as temperature and rainfall are important factors that are directly related with the growth of vectors and mosquitoes.

Malaria cases in the states of Khartoum and Kassala have only been affected by the previous malaria cases; this indicates that the climate variability did not affect malaria transmission. This result agrees with previous studies on climate variables and the transmission of Falciparum malaria in New Half, eastern Sudan [13]. Himeidan concludes that temperature, relative humidity and water irrigation are not significant in concurrence with the present study. The climatic factors for Khartoum and Kassala states were not significant, which can be interpreted as the malaria transmission being man-made through urban malaria. [16]revealed that urban malaria is associated with socio-ecological and socio-economic factors, such as biomass factors, quality of housing and topographical. The rainfall was not significant in Northern, River 
Nile and Red Sea states to the transmission of malaria, this is because of the lack of rainfall in these areas; the average annual rainfall was around $4.47 \mathrm{~mm}, 0.28 \mathrm{~mm}$ and $6.35 \mathrm{~mm}$ for the River Nile, Northern and Red Sea states, respectively, compared to the annual average of an overall area exceeding $26 \mathrm{~mm}$, this result agrees with [3] who revealed that the minimum rainfall requirement for development mosquito to transmission malaria was around $80 \mathrm{~mm}$ per month for three months of rain. The Northern and Red Sea states did not have any significant of malaria cases with the previous malaria cases, similar to studies[11, 17], this result can be explained that these two states (Northern and Red Sea) have smallest malaria cases compared to the rest of the Sudan except South Darfur, in addition there are various socio-economic factors, such as immigration from rural to urban and population attitudes. Generally, there are variations in the impact of climatic factors for the spread of malaria among states in Sudan, this result is consistent with a number of previous studies such as[6], who investigated the association between autoregressive (number of malaria outpatients during the previous time period), seasonality and climate variability, and the number of monthly malaria outpatients in East Africa. Zhou found that there was a high spatial variation in the sensitivity of malaria outpatient numbers to climate fluctuations in the highlands, and that climate variability played an important role in malaria epidemics in the East African highlands. [11], using monthly malaria cases and the meteorological data in seven malaria endemic districts, found that the mean maximum temperature lagged at one month was a strong positive predictor of increased malaria cases for four districts. [11, 17] used ARIMA models with seasonal components, and seasonal multiplicative autoregressive integrated moving average (SARIMA) models were compared on monthly time series of district malaria cases for their ability to predict the number of malaria cases one to four months ahead. [17]concluded that the addition of rainfall as a covariate improved the prediction of selected (seasonal) ARIMA models in some districts but worsened prediction in other districts.

\section{CONCLUSION}

The time series seasonal ARIMA model showed that there are four distinct models across the study area; therefore, any malaria control programme must be treated separately. The average monthly maximum temperature, minimum temperature and rainfall are predictor variables; the ARIMAX model illustrated that different states responded to different models. Some states only show significance to previous malaria cases, while other states appear significant to predictor variables. The ARIMA model used by the present study can be useful to other diseases such as dengue. However, further research is recommended to forecasting malaria using other variables such as the malaria control programme, immigration between and within states and behavior of population.

\section{ACKNOWLEDGEMENTS}

We are grateful to the Malaysian Technical Cooperation Program (MTCP) for financial support; many thanks to the Economics and Social Research Bureau (ESRB), Ministry of Science and Technology Sudan.

\section{REFERENCES}

[1] NMCP,“The National Protocol for Treatment of Malaria”, Sudan: National Malaria Control Program Sudan, 2004.

[2] Musa MI., et al.,"Environmental and Socio-Economic Determinants of Malaria Rate in Sudan”,Research Journal of Environmental and Earth Sciences, vol/issue: 4(11), pp. 923-929, 2012.

[3] Adjuik M., et al.,“Towards an atlas of malaria risk in Africa”,First technical report of the Mapping Malaria Risk in Africa/Atlas du Risque de la Malaria en Afrique (MARA/ARMA) collaboration. Durban, MARA/ARMA,1998.

[4] Onori E., Grab B.,"Indicators for the forecasting of malaria epidemics”,Bulletin of the World Health Organization, vol/issue: 58(1), pp. 91, 1980.

[5] Martens WJ., et al.,"Potential impact of global climate change on malaria risk”,Environ Health Perspect, vol/issue: 103(5), pp. 458-464, 1995.

[6] Zhou G., et al.,"Association between climate variability and malaria epidemics in the East African highlands”, Proceedings of the National Academy of Sciences of the United States of America, vol/issue: 101(8), pp. 2375, 2004.

[7] NMCP,“The National Protocol for Treatment of Malaria”, Khartoum, Sudan: National Malaria Control Program Sudan, 2006.

[8] Lusingu J., et al.,"Malaria morbidity and immunity among residents of villages with different Plasmodium falciparum transmission intensity in North-Eastern Tanzania”,Malaria Journal, vol/issue: 3(1), pp. 26, 2004.

[9] Brocklebank JC., Dickey DA.,"SAS for forecasting time series”, SAS Publishing, 2003.

[10] Tian L., et al., "One-year delayed effect of fog on malaria transmission: a time-series analysis in the rain forest area of Mengla County, south-west China”,Malaria Journal, vol/issue: 7(1), pp. 110, 2008. 
[11] Wangdi K., et al.,"Development of temporal modelling for forecasting and prediction of malaria infections using time-series and ARIMAX analyses: A case study in endemic districts of Bhutan”,Malaria Journal, vol. 9, pp. 251, 2010.

[12] Musa MI., et al.,“A climate distribution model of malaria transmission in Sudan”,Geospatial health, vol/issue: 7(1), pp. 27-36, 2012.

[13] Himeidan YE., et al.,"Climatic variables and transmission of falciparum malaria in New Halfa, eastern Sudan”,Eastern Mediterranean Health Journal, vol/issue: 13(1), pp. 17, 2007.

[14] Box G., Jenkins G., “Time series analysis: forecasting and control Holden Day”,San Francisco, pp. 51-65, 1976.

[15] Rao CR., et al.,“Epidemiology and Medical Statistics”, Netherlands: Elsevier, 2008.

[16] Bray RS.,Garnham PCC., “The life-cycle of primate malaria parasites”,British Medical Bulletin, vol/issue: 38(2), pp. 117, 1982.

[17] Briet OJ., et al.,"Models for short term malaria prediction in Sri Lanka”,Malaria Journal, vol/issue: 7(1), pp. 76, 2008. 